\title{
Externalities of Soil Stabilization in the Construction of Main Transporta- tion Infrastructures. The Case of the High Speed Railway in North Italy: Economical and Environmental Benefits
}

\author{
Andrea Benedetto* \\ Department of Sciences of Civil Engineering - University Roma Tre, Via Vito Volterra, 60 - 00146 Rome - Italy
}

\begin{abstract}
The technique of soil stabilization is usually adopted with the purpose of rendering plastic soils coherent to the standards and requirements of engineering projects. The environmental benefits of soil stabilization versus the use of traditional natural material from quarries are generally underestimated. The case study of one significant section of the Italian High Speed Railway is presented here. This section is a part of the line from Milan to Venice. The volume of material that is needed for the development of embankments amounts to about 3 million $\mathrm{m}^{3}$ and 1.5 millions $\mathrm{m}^{3}$ of aggregates are needed for concrete. At the same time the construction of foundations produces about 1 million $\mathrm{m}^{3}$ of soil: $350,000 \mathrm{~m}^{3}$ from foundations, 400,000 $\mathrm{m}^{3}$ from diaphragms and drilled piles and 70,000 $\mathrm{m}^{3}$ from helicoidal piles. The need to manage such a significant volume of soil suggests the need for the consideration of recycling the clay soil after lime stabilization. The technical compatibility is here verified. The total costs of all the actions derived from the Environmental Impact Assessment for environment protection is less than $8 \%$ of the savings produced by the stabilization of soil. It finally demonstrates that the question of non-renewable resource management, such as soil, is strategic also under an environmental protection perspective.
\end{abstract}

\section{INTRODUCTION}

Air pollution, noise and vibrations, impacts on ecological balances or sometimes on flora and fauna, risk of water contamination, electromagnetic induction are considered the main environmental questions related to the construction and operation of transport systems. Scientific and professional communities all over the world are involved in the study of these questions engaging human and financial resources. In the last decade the know-how in this field has increased and the knowledge widely disseminated [1]. However there are issues related to the construction of infrastructures that are often neglected in terms of environmental assessment. Sometimes they have implications to the environment that are much more relevant in addition to traditional questions such as noise or air pollution. This is the case in the use of alternative materials, stabilization of soil and recycling, which is the topic of this paper.

The technique of soil stabilization is usually adopted with the purpose of rendering plastic soils coherent to the standards and requirements of engineering projects. The issue is always considered under a construction perspective and environmental benefits are often neglected.

These techniques have a long history. It was used in ancient Mesopotamia and Egypt, and Greeks and Romans later used soil and lime mixes to increase the stability of roads [2].

The first application on a significant scale was carried out in 1924 in the United States for short sections of federal motorways [3]. The first standards for soil stabilization using lime are relatively recent [4].

*Address correspondence to this author at the Department of Sciences of Civil Engineering - University Roma Tre, Via Vito Volterra, 60 - 00146 Rome - Italy; Tel: +39-06-55173543; Fax: +39-06-55173441;

E-mail: benedet@uniroma3.it
In the thirties the use of lime for stabilization of plastic soils increased greatly, especially in the USA, but the most important diffusion of the technique was during and immediately after the second world war, in consequence of the enormous increase in the number of motor vehicles.

More recently lime stabilization for the development of roads and railways has become a widely used technique in industrialized countries, from North America [5-8], to Australia [9] and in many European countries [10] and, surprisingly, in a few of developing countries (i.e. in Giordania [11]; in Ghana [12, 13]; in India [14, 15]; in Turkey [16]).

The excellent results of stabilization in many constructions $[17,18]$ and the promising frontiers for new applications, pressed researchers and engineers to write manuals and handbooks [19-22] and to develop standard operating procedures [23] and quality controls [24] (see Table $\mathbf{1}$ for the standards).

Adding lime to clay soils has an immediate binding effect induced by the cation exchange between the metallic ions from the surface of clay particles and the calcium ions of lime. These ions saturate the electrical poles of water molecules that are around the clay particles and these particles are attracted closer to each other. This attraction makes the clay particles form flocks. The flocks change the grading of soil from ultra-fine micrometric particles to millimetre size particles that consequently change their mechanical properties. This process is immediate and occurs in the presence of a low percentage of lime (generally from 1 to maximum 3\% by weight) and is commonly referred as lime fixation or soil modification [25].

When the percentage of added lime is higher (generally from 3 to $8 \%$ ) chemical reactions occur: alumina-silicates 
Table 1. ASTM and AASHTO Standards for Lime Stabilization

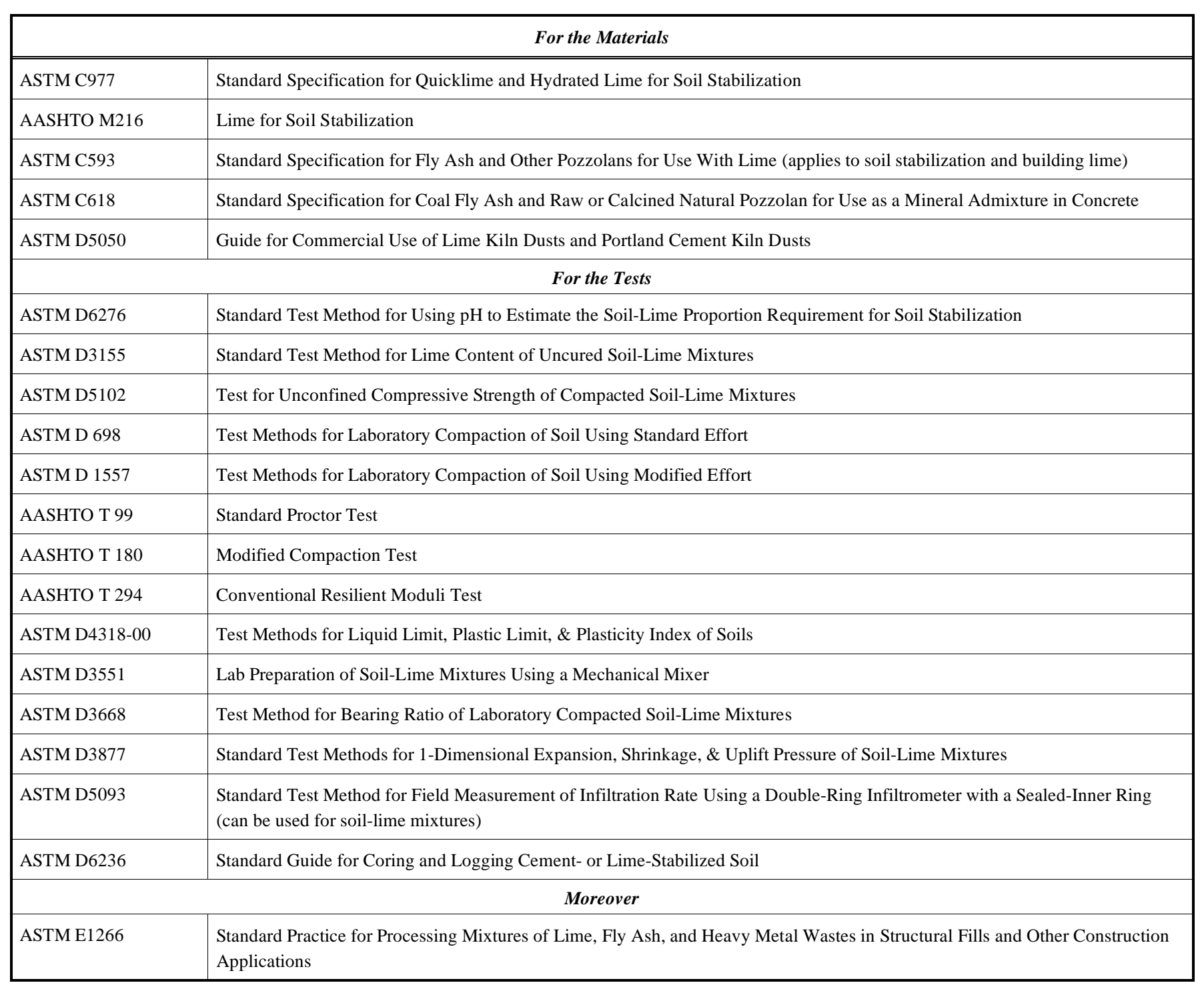

precipitate as hydrated cementitious in an alkaline environment produced by lime.

In this case the soil chemically changes its own properties and the process is properly referred to as stabilization. Stabilizing the soil increases mechanical properties not only in the force of grading changes but also for pozzolanic binding reactions that contribute to develop strength gradually over a long period of time [26].

Basically all types of clays react with lime, but the reactions can be different in kinetics or effectiveness depending on mineral composition. Clay soils with monmorillonite react significantly with lime and the cation exchange is relevant. Kaolinitic clays are less sensitive to lime [27].

The evidence from the literature demonstrate that from a mechanical point of view the properties of plastic clay soils after stabilization with lime in adequate percentages are coherent to required standards for unbound layers (subgrade and subbase) of roads and railway constructions.

More in depth, the effect of stabilization is quantified by a significant increase in the Atterberg Plastic Limit and by a relevant reduction of plasticity (Plastic Index). CBR values increase with aging, from 4 to 10 times the original value after 2 hours and over 100 times for the long term. The mechanical behaviour stress-strain changes from viscousplasticity towards elasticity. For long periods of time, the modulus of elasticity increases up to 10 times the value of the modulus of the original clay soil. The effect of stabilization is evident also in the standard compaction test (Proctor test). The maximum value of dry densities decreases and simultaneously the value of optimum moisture content for compaction increases [28].

All these considerations demonstrate the relevant benefits of stabilization under a structural and mechanical perspective [29-31], but significant benefits have to be underlined under an environmental protection perspective and many times also under a financial one.

The specific objectives of this work are to validate the applicability of soft soil stabilization to High Speed Railway development and to assess the environmental positive impacts of the soil reuse. The soil stabilization in High Speed Railway construction has been rarely used but the environ- 
mental benefits have never been quantified. This work gives a first useful methodological contribution through the presentation of a very important study case at the national and European level.

The case of Italy is anomalous because soil stabilization is currently not diffused as expected. Strong pressure for the use of stabilized soils came up in Italy at the end of nineties for the development of a High Speed Railway in the North of the country from Milan to Bologna. Here only clay soils are available on site. Without extensive stabilization an enormous amount of clay soils extracted from cuts, foundations, piles, and plinths should have been disposed as waste and, at the same time, volumes of adequate material should have been extracted from natural sites and transported to the yards.

\section{LIME STABILIZATION OF CLAY SOILS}

Stabilization of clay soils implies not only environmental benefits such as the saving of significant amounts of nonrenewable resources, but sometimes relevant benefits from a financial point of view, if compared to the traditional approach using natural materials extracted from quarries. The financial advantages from stabilization are difficult to be calculated because they depend on many factors such as the distances of quarries, the characteristics of materials, the structure and logistics of yards, the available machines, and the cost of waste disposal. Considering all of these uncertainties, any generalization evaluating costs and benefits is completely unreliable. The assessments have to be developed case by case. Here, some considerations that can be assumed to be objective and commonly found in the technical literature are briefly summarized.

The construction of embankments using natural soil extracted from quarries without stabilization typically is developed in the following phases: acquisition of material, transport and dumping, arrangement of soil in layers of adequate thickness using a bulldozer or grader, compaction with vibrator steamroller.

If there is no limitation with the material supply, the volume of embankment that can be constructed in one day by a work team can be over $2000 \mathrm{~m}^{3}$. The costs are for $90 \%$ of material acquiring and transport and for $10 \%$ of the work of the team. A portion of the $90 \%$ accounts for the transport from the quarry to the yard, and moreover the associated environmental (air and noise pollution) and societal costs (quality of life deterioration) should not be neglected.

The construction of an embankment using lime stabilized soil typically is developed in the following phases: excavation and short transport of soil inside the yard to the construction site, arrangement of soil in layers of adequate thickness using a bulldozer or grader, milling using a pulvimixer, lime mixing, levelling of the layer and compaction. The volume of the embankment that can be constructed in one day by a work team can be about $3000 \mathrm{~m}^{3}$, but it depends on the soil characteristics, the weather, and the capacity of recycling machines. The costs are $40 \%$ for material, $40 \%$ for the machines and $20 \%$ for the work of the team.

In general, extrapolating from previous experiences and on the basis of consolidated know-how, when the balance between excavated and filling volume produces a significant soil surplus, the option of lime stabilization has to be considered in order to save $30 \%$ of financial costs in respect to traditional construction methods.

\section{ENVIRONMENTAL ASPECTS}

The environmental benefits of soil stabilization versus the use of traditional natural material from quarries are generally underestimated. Especially if it happens in countries where natural materials are relatively abundant and where the cost of waste disposal is low. The main environmental benefits concern: the saving of natural resources and the preservation of the landscape by quarry prevention, decreasing the production of solid waste and consumption of area for disposal, the heavy reduction of air pollution and noise as a consequence of the reduction of material transport.

Generally these benefits are not quantified in feasibility studies nor in the Environmental Impact Assessment.

The relevance of positive environmental impacts can be evaluated through a comparison among all impacts. Of course such a comparison is possible only if the impacts were measured homogeneously. Approximately the cost of impact mitigation is here assumed as a measure of the impact itself. Under this hypothesis all impacts can be assumed under a homogeneous measurement.

For example the average level of noise before the construction of a railway is $N_{\mathrm{a}}$ [dBA]; as the trains operate the level of noise is $N_{\mathrm{b}}$ [dBA]. To reduce noise from $N_{\mathrm{b}}$ to $N_{\mathrm{a}}$ noise protection systems (barriers, windows isolation, trees, artificial hills...) are needed. The total cost for the system for the abatement of noise for $N_{\mathrm{b}}-N_{\mathrm{a}}$ [dBA] is assumed as the magnitude of the noise impact. This evaluation is not difficult and it can be carried out using simulation models to predict the noise level and to design the protection system.

Analogously the magnitude of air pollution, waste production, natural resources consumption, or tree cutting, or other generic impacts can be evaluated as standard cost. If the full reduction of the impact to "ex ante" conditions is not possible, the cost of mitigation to the minimum reasonably acceptable value can be assumed.

Under this approach it is possible to evaluate the approximated relevance of environmental impacts using an objective and repeatable method.

\section{CASE STUDY}

The case study of one significant section of the Italian High Speed Railway is presented here. This section is a part of the line from Milan to Venice.

Problems with construction material provisioning are relevant in the stretch of railway around the city of Modena. Here the projected route develops for about $40 \mathrm{~km}$ on two tracks on new compacted embankments, and for $8 \mathrm{~km}$ of an additional track on existing embankments. Moreover an interconnected system to the old railways and a few viaducts for the HS railway complete the works for about $22 \mathrm{~km}$ of viaducts, for the so called Modena Viaducts System (Fig. 1). This system lays on clay soils with high plasticity and with a very low value of CBR. 

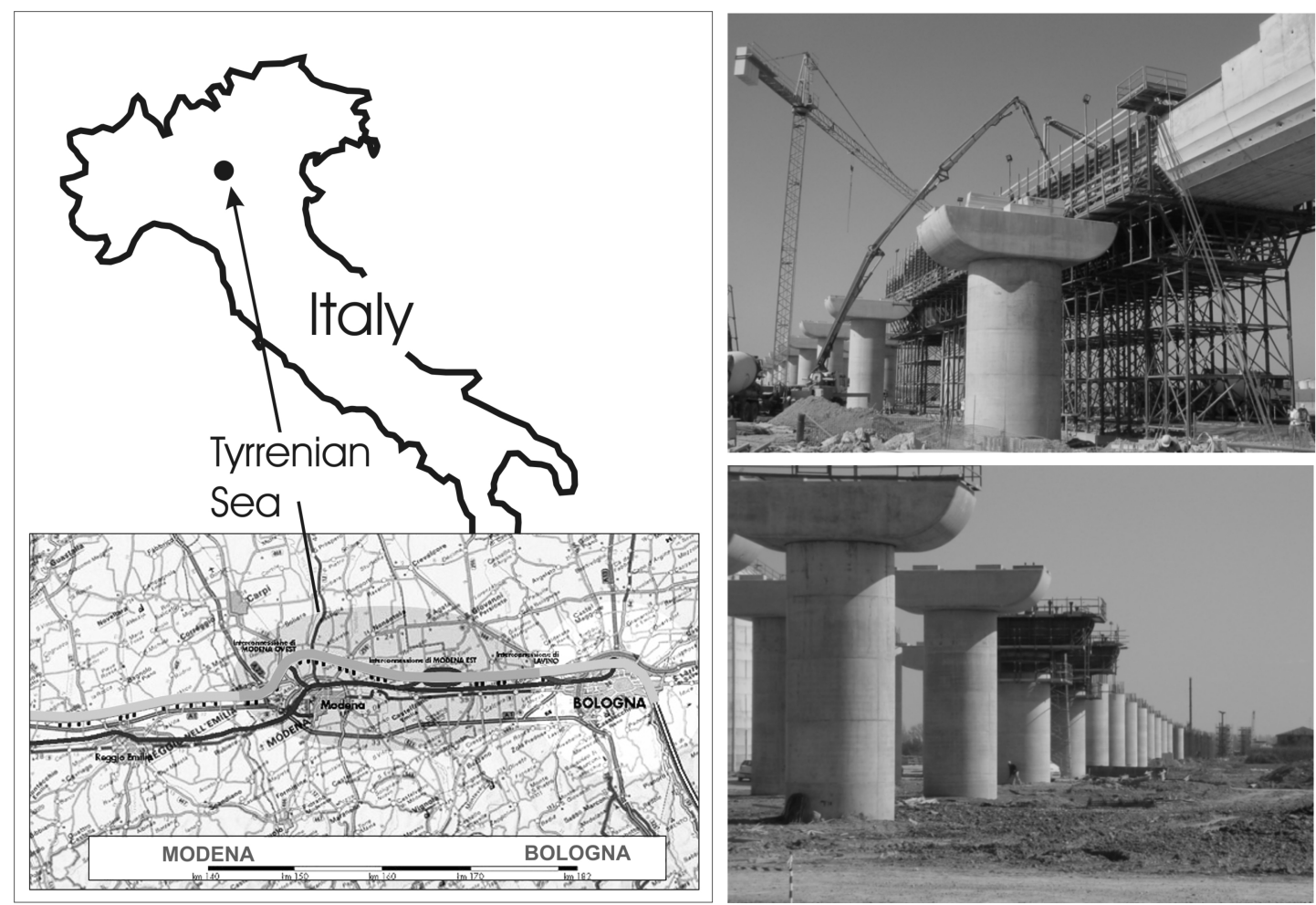

Fig. (1). Modena Viaduct System.

These viaducts have to be founded on drilled piles with a diameter of $1500 \mathrm{~mm}$, between 35 and $50 \mathrm{~m}$ deep. The piles are alternated to rectangular diaphragms and over the piles plinths of about $300 \mathrm{~m}^{3}$ (for each track) are constructed as foundations for the railway structure.

The development of piles and plinths implies the extraction of a consistent volume of clay soil that is not adequate as is for construction applications, and in compliance Italian law, it has to be disposed as waste.

In this case there are simultaneously a relevant need for adequate soil for construction of embankments and an enormous volume of soil to be disposed. The management of material becomes the most important activity for containing the environmental impact both as waste production and disposal, both as natural non-renewable resources (soil) consumption. Moreover it has to be underlined that adequate natural soil is not available next to the yard (Po River Valley) and transport from Apennines or Alps, which is a distance over $50 \mathrm{~km}$, is needed.

The volume of material that is needed for the development of embankments amounts to about 3 million $\mathrm{m}^{3}$ and 1.5 millions $\mathrm{m}^{3}$ of aggregates are needed for concrete. At the same time the construction of foundations produces about 1 million $\mathrm{m}^{3}$ of soil: $350,000 \mathrm{~m}^{3}$ from foundations, $400,000 \mathrm{~m}^{3}$ from diaphragms and drilled piles and $70,000 \mathrm{~m}^{3}$ from helicoidal piles.

The need to manage such a significant volume of soil suggests the need for the consideration of recycling the clay soil after lime stabilization. The impact of possible recycling is important both under an environmental perspective and from an economical point of view. Of course the technical compatibility has to be verified.

\subsection{Soils Extracted Along the Route}

The soils extracted from excavation for the development of plinths, piles and foundations are basically homogeneous and highly plastic. Along the $40 \mathrm{~km}$ of the projected route 127 cores have been drilled and the samples have been tested in the laboratory. The soils are classified as A6 and A7-6 under AASHTO classification. About the $90 \%$ of material passes at $75 \mu \mathrm{m}$ grading analysis. Atterberg Plastic Limit (PL) is approximately $10-15 \%$ in the first $20 \mathrm{~km}$ of the route, is about $15-20 \%$ in the following $10 \mathrm{~km}$, and in the last part of the route PL increases to $20-25 \%$. The average values of the mean geotechnical characteristics of samples are summarized in Table 2.

Such natural materials are obviously not adequate for embankments construction, but simultaneously they are generally good for lime stabilization.

A little part of the materials extracted from drilled piles had local intrusion of sand and gravel that discouraged recycling after stabilization, considering that lime mixing could be ineffective. These materials have been reused for secondary roads and ramps for the yards.

\subsection{Preliminary Tests}

According to the literature, a three percent compositions of lime have been assumed to stabilize the soil: $2 \%, 2.5 \%$ and 3\%. The effect of lime mixing on Atterberg limits is to increase the liquid and plastic limits (LL and PL). PL increases from $21 \%$ to $30 \%$ and LL from 44 to $48-50 \%$. The 
Table 2. Geotechnical Characteristics of Soil

\begin{tabular}{|c|c|}
\hline Variable & Average Value \\
\hline \hline Liquid Limit (\%) & 44 \\
\hline Index of Plasticity (\%) & 23.5 \\
\hline USCS classification & $\mathrm{CL}$ \\
\hline Nitrate (\%) & 0.03 \\
\hline Initial Lime Content $(\%)$ & 2 \\
\hline $\mathrm{w}_{\mathrm{opt}}(\%)$ & 17.3 \\
\hline$\gamma_{\mathrm{d}, \text { max }}\left(\mathrm{kN} / \mathrm{m}^{3}\right)$ & 16.64 \\
\hline Immediate Bearing Index $(\%)$ & 10 \\
\hline CBR $(\%)$ & 3 \\
\hline
\end{tabular}

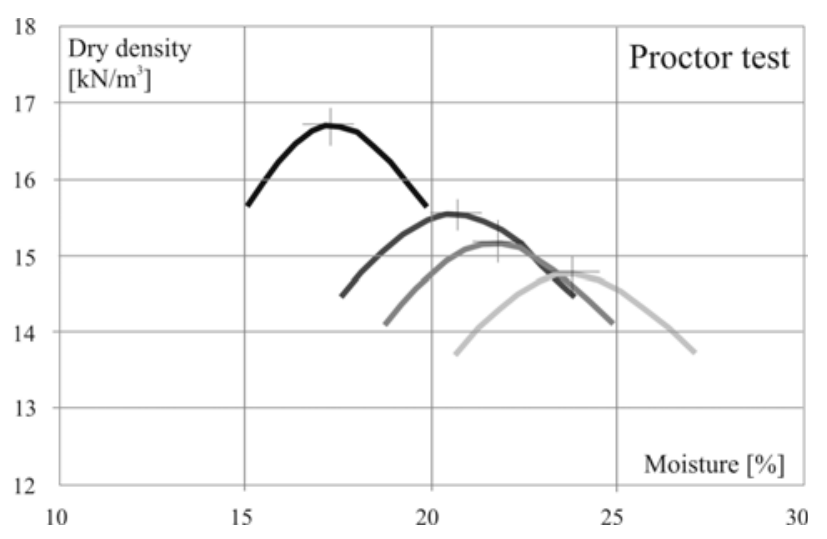

Fig. (2). Dry density after stabilization.

Plasticity Index (IP=LL-PL) decreases to $18 \%$ from $24 \%$. Compaction test (Proctor), bearing tests (CBR and immediate bearing index) and vertical compression tests were carried out. The results demonstrate that the mechanical properties of the stabilized soil increase over the expectations, especially for 3\% lime. In particular Fig. (2) shows that dry density decreases if the lime increases from $16.6 \mathrm{kN} / \mathrm{m}^{3}$ for the natural soil to $14.8 \mathrm{kN} / \mathrm{m}^{3}$ by adding $3 \%$ lime. The optimum value of the compaction moisture increases from $17 \%$ to $24 \%$.
Fig. (3) shows the increase in the immediate bearing index when lime is added as a function of water content. The effect of stabilization is low at short time durations because the pozzolanic reactions are in progress; this is why the immediate bearing index increases to about $25 \%$ while CBR after 28 days aging increases from $3 \%$ (natural material) to almost $70 \%$.

Vertical compression tests demonstrated that compressive strength increases after 28 days of aging around $900 \mathrm{kPa}$. Fig. (4) shows that a three percentage composition of lime has a similar effect for the long term, and compressive strength increases approximately from $350-400 \mathrm{kPa}$ after three days to $880-940 \mathrm{kPa}$ after 28 days.

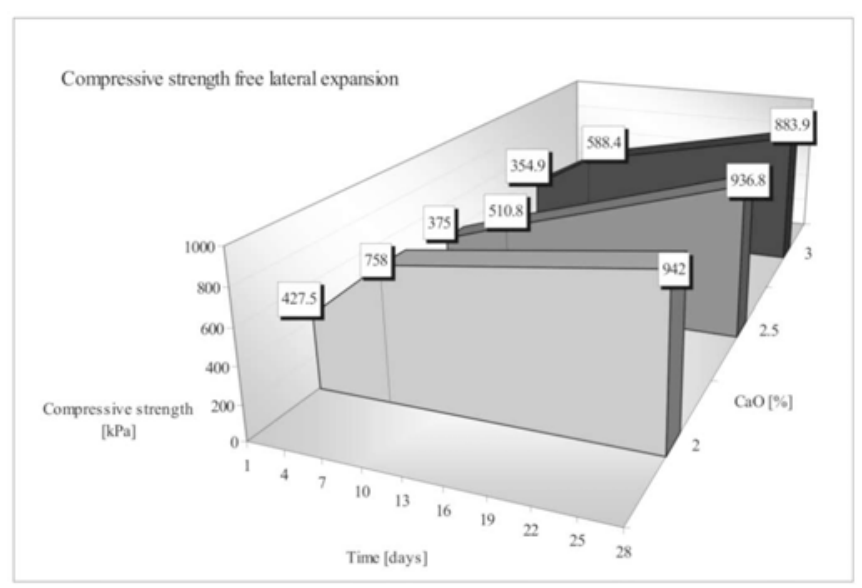

Fig. (4). Long term effects of stabilization: compressive strength.

Preliminary tests supported the choice for the best percentage of lime. The value of $3 \%$ was adopted for the site tests on a real scale because all samples of stabilized soils with $3 \%$ lime had mechanical characteristics significantly higher than the standard requirements for High Speed Railway construction.

\subsection{Site Tests on Real Scale}

Starting from the outcomes of the preliminary tests a wide experimental campaign was carried out in order to assess: the best technology and the best methodology to compact stabilized soil, the reliability of laboratory results with respect to real scale construction. Four fields were prepared

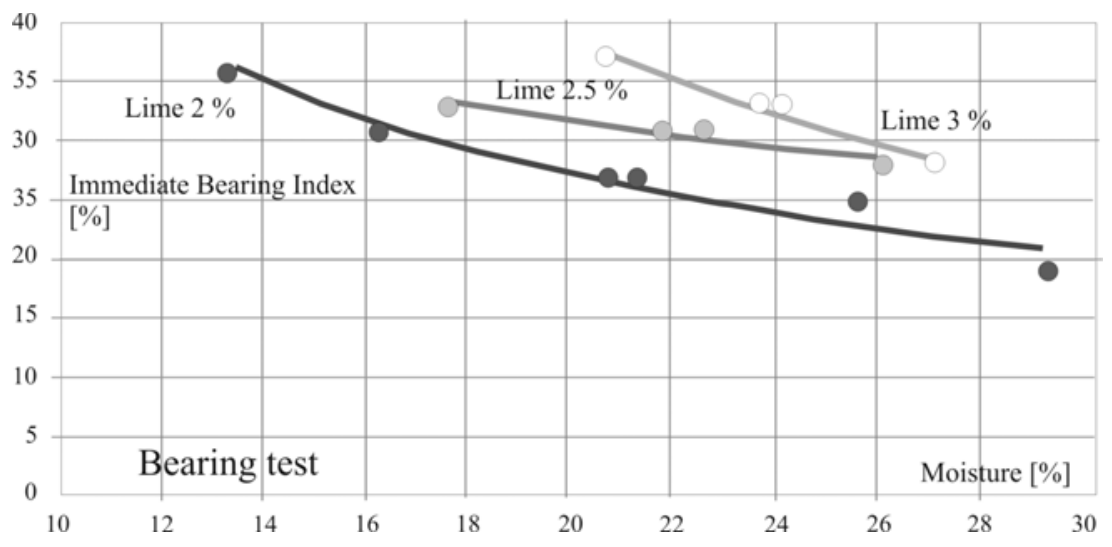

Fig. (3). Immediate bearing index after stabilization. 
Table 3. The Site Tests

\begin{tabular}{|c|c|c|c|}
\hline Site & Objectives of the Tests & Site Dimensions & Evidences \\
\hline \multirow{3}{*}{ Site A } & Identification of the best $\%$ of lime & \multirow{3}{*}{$60 \times 10 \mathrm{~m}$} & Best lime content $=3 \%$ \\
\hline & $\begin{array}{l}\text { Validation of different compaction } \\
\text { methods }\end{array}$ & & $\begin{array}{c}\text { Compaction method } \mathrm{C} 1= \\
1 \text { Cycle static steamroller }+1 \text { Cycle vibrating steamroller }+4 \text { Cycles static } \\
\text { steamroller }\end{array}$ \\
\hline & $\begin{array}{l}\text { Identification of the best depth for lime } \\
\text { stabilization }\end{array}$ & & Best depth for soil stabilization and compaction $=0.30 \mathrm{~m}$ \\
\hline Site B & $\begin{array}{l}\text { Validation of stabilization and compac- } \\
\text { tion treatment using an geo-synthetic } \\
\text { over or under the natural soil level }\end{array}$ & $50 \times 18 \mathrm{~m}$ & The mechanical tests accord to the requirements for High Speed Railway \\
\hline \multirow{3}{*}{ Site $\mathrm{C}$} & $\begin{array}{l}\text { Validation of different compaction } \\
\text { methods }\end{array}$ & \multirow{3}{*}{$30 \times 220 \mathrm{~m}$} & The results confirm the best compaction method is $\mathrm{C} 1$ \\
\hline & $\begin{array}{l}\text { Identification of the best method for } \\
\text { lateral slopes construction and compac- } \\
\text { tion }\end{array}$ & & $\begin{array}{l}\text { The construction and compaction slopes of embankments are identified and } \\
\text { tested }\end{array}$ \\
\hline & Validation on real scale of the treatment & & $\begin{array}{l}\text { The real scale outcomes confirm the laboratory scale outcomes and accord to } \\
\text { the requirements }\end{array}$ \\
\hline Site D & $\begin{array}{l}\text { Feasibility study of polymeric materials } \\
\text { for stabilization of soil from pile excava- } \\
\text { tion }\end{array}$ & $30 \times 60 \mathrm{~m}$ & No reliable results \\
\hline
\end{tabular}
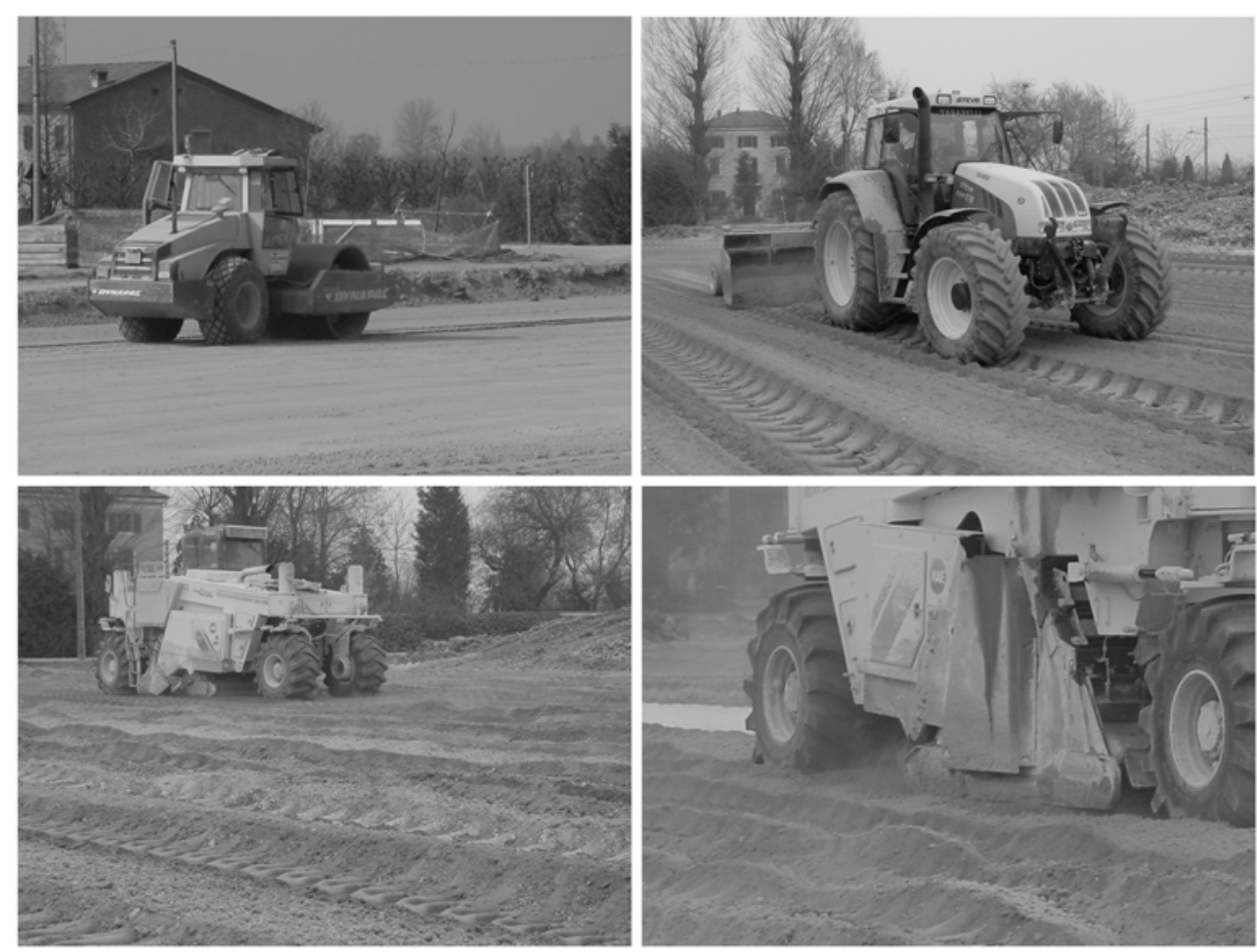

Fig. (5). Test field.

for tests. The dimensions, the specific objective of each field, the origin of the stabilized soil and the expected application are described in Table $\mathbf{3}$.

The site tests confirmed the promising evidence obtained from laboratory tests.
In fact, according to the laboratory test, the optimal percentage of lime for the best mechanical properties of the stabilized mixes is $3 \%$. Three different compaction procedures have been tested: $(\mathrm{C} 1)$ one cycle with a static steamroller $(18,500 \mathrm{~kg})$, on'e cycle with a vibrating steamroller and four cycles with a static roller (Fig. 5); (C2) four cycles with a 


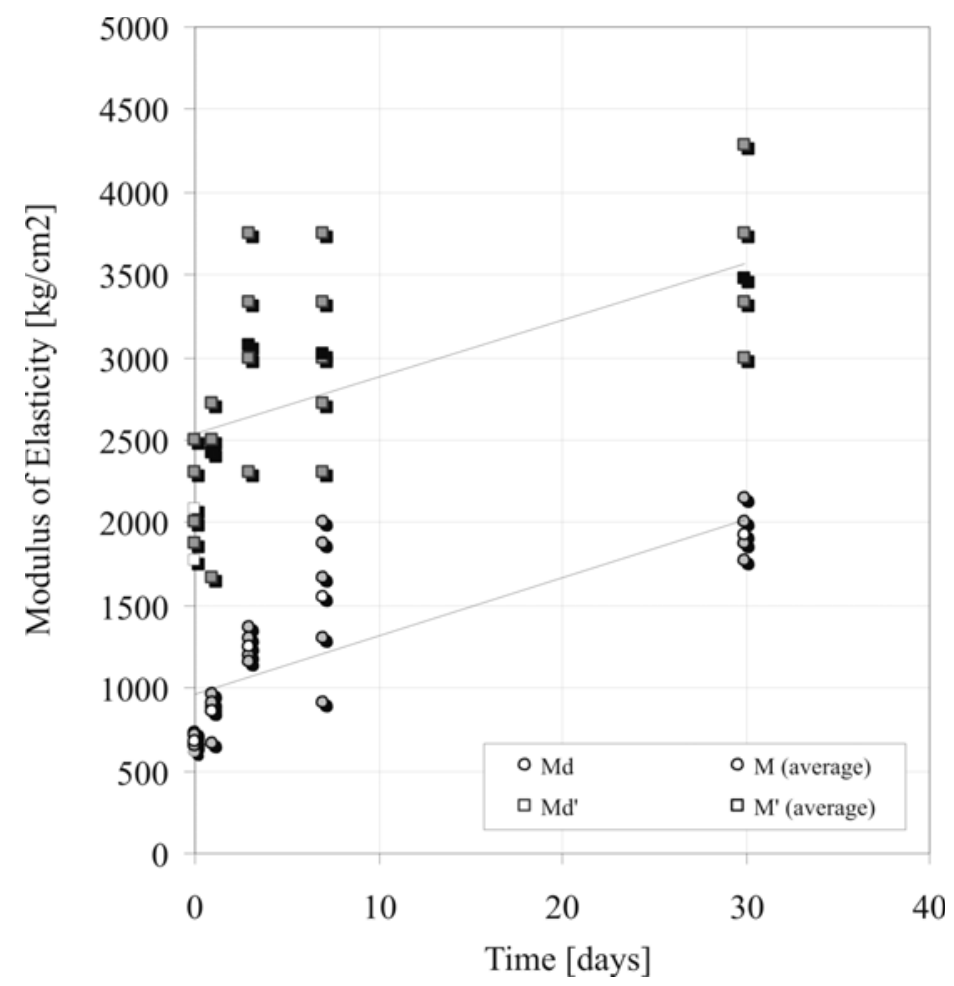

Fig. (6). Modulus of elasticity in two consecutive tests after compaction.

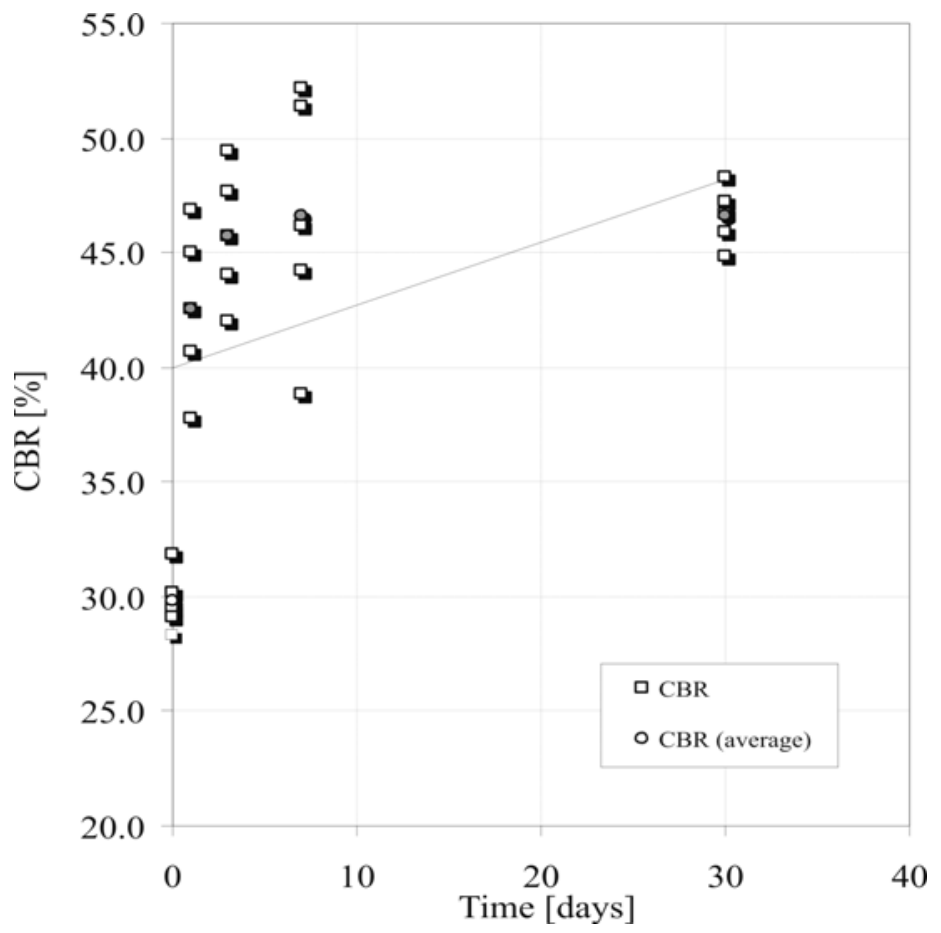

Fig. (7). CBR increasing after aging.

vibrator plugged steamroller, one cycle with a grader and one cycle with a static roller; (C3) four cycles with a vibrator plugged steamroller and one cycle with a static roller. The procedures $\mathrm{C} 2$ and $\mathrm{C} 3$ are usually more effective with plastic soils rather than procedure $\mathrm{C} 1$, but in this case with lime stabilized soil, the mechanical properties of mix changes from plastic to elastic such that the best compaction procedure is unexpectedly, C1. The maximum thickness of the layer to reach adequate mechanical characteristics is $30 \mathrm{~cm}$. For thicker layers the stabilization does not produce such good results.

The Modulus of elasticity measured in two consecutive tests on site increases after compaction and 30 days of aging to $1,500 \mathrm{~kg} / \mathrm{cm}^{2}$ for the first test and for the second test to $3,000 \mathrm{~kg} / \mathrm{cm}^{2}$ (Fig. 6). These values of the modulus are much 


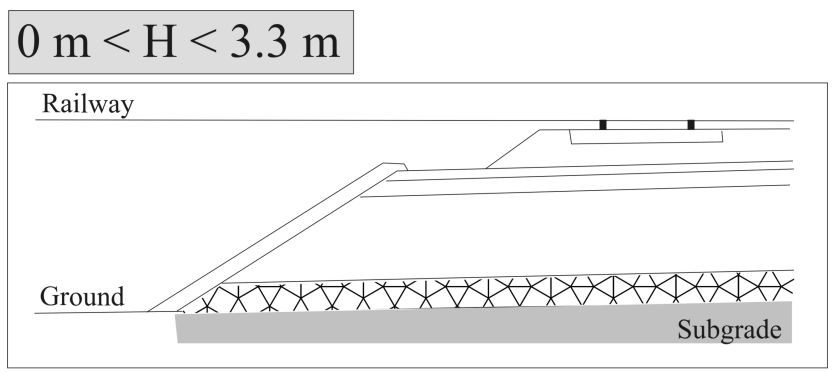

\section{$3.3 \mathrm{~m}<\mathrm{H}<5 \mathrm{~m}$}
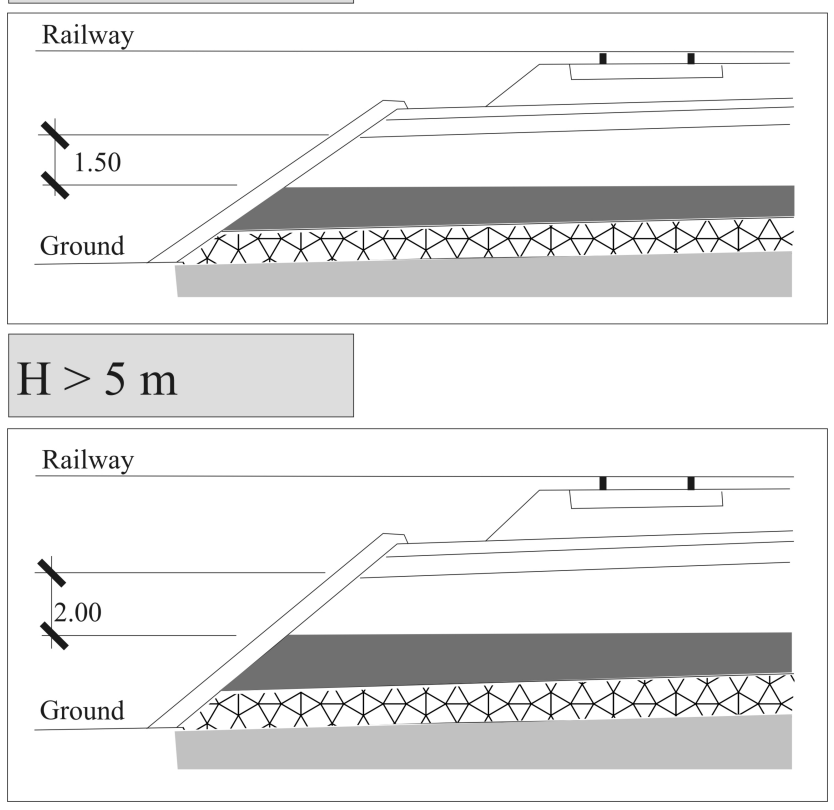

Fig. (8). Stabilized soil for railway embankment construction according to Italian regulations.

higher than the requirements for soil to be used for embankments of the Italian High Speed Railway.

Analogously the values of CBR obtained from the experimental fields increase from $30 \%$ after construction to $47 \%$ after 30 days of aging (Fig. 7). The CBR of the original, not stabilized soil is $3 \%$.

\subsection{Construction Options}

The results of tests demonstrated that the soil after correct stabilization using lime at adequate percentages is suitable for the construction of embankments. The current Italian technical regulation for High Speed railway development does not make possible the use of stabilized soils for the construction of the entire embankment. Stabilized soil can be used (only from 1998) only for the lower layer as in Fig. (8). The regulation does not take into account the mechanical performances of stabilized soils.

To make a reasonable comparison in terms of the benefits of using stabilized soils for railway development, three possible options have been considered (Fig. 9): (1) construction of embankments with natural adequate soil extracted from quarries, (2) construction of embankments partially using stabilized soil in accordance with Italian regulations, (3) construction of embankments using only stabilized soil that
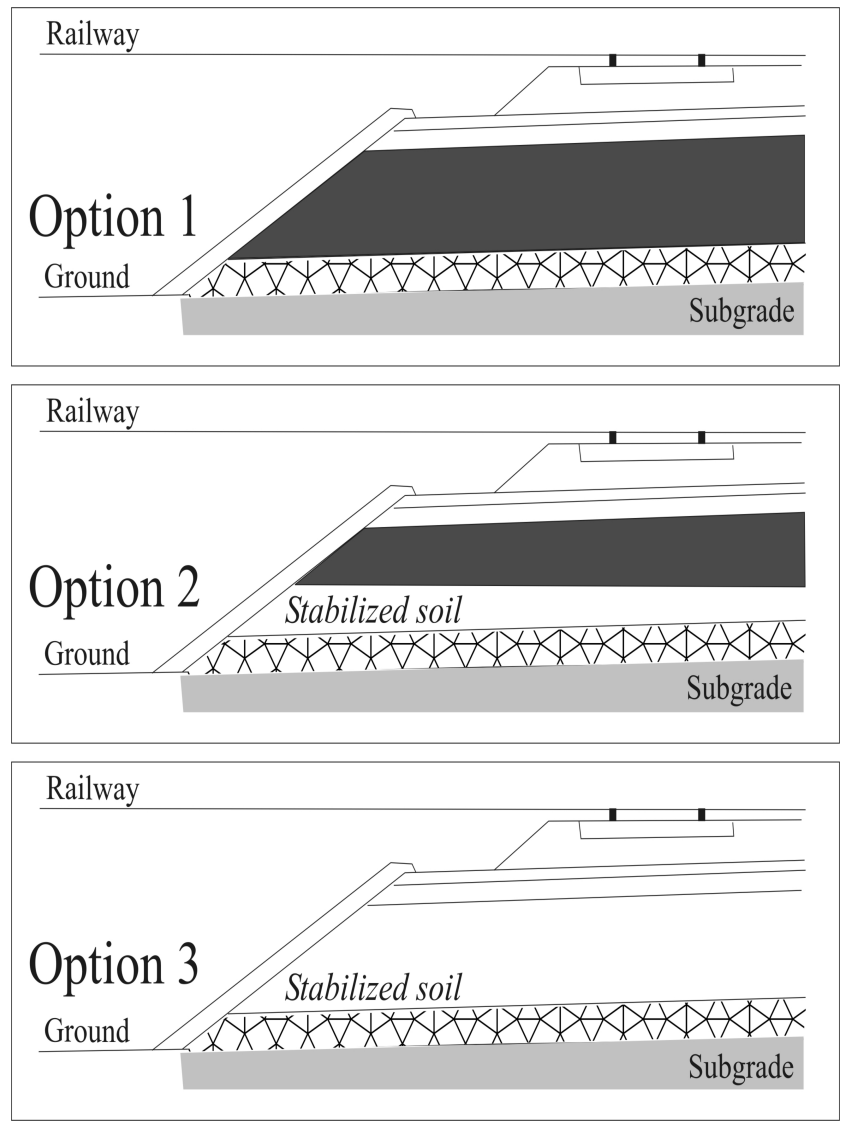

Fig. (9). Schemes of the three considered options.

is adequate from a mechanical point of view as demonstrated by laboratory and real scale tests. The environmental and financial impacts of these three options will be synthetically discussed.

\section{FINANCIAL AND ENVIRONMENTAL ASSESS- MENT: DISCUSSION}

The costs of construction of this section of railway in the three mentioned options have been evaluated as follows. Table 4 shows the volume of different materials that should be used under the three options.

Assuming the average costs of providing material and transport, considering the different costs of construction and compaction using different techniques and the cost of waste management and disposal, the total costs are compared in Table 5.

The available quarries have been identified at a maximum distance of $50 \mathrm{~km}$ from the construction site. According to the real available volume to be extracted, these quarries have been selected in three categories to account different transportation costs: quarries $\mathrm{A}$ are maximum $15 \mathrm{~km}$ far from the work site, quarries B from 15 to $30 \mathrm{~km}$ and quarries C more than $30 \mathrm{~km}$ (see Table 5).

The cost of construction in the second case is more than $30 \%$ lower and in the third case it is about $70 \%$ lower. Of 
Table 4. Volume of Materials According to Different Options

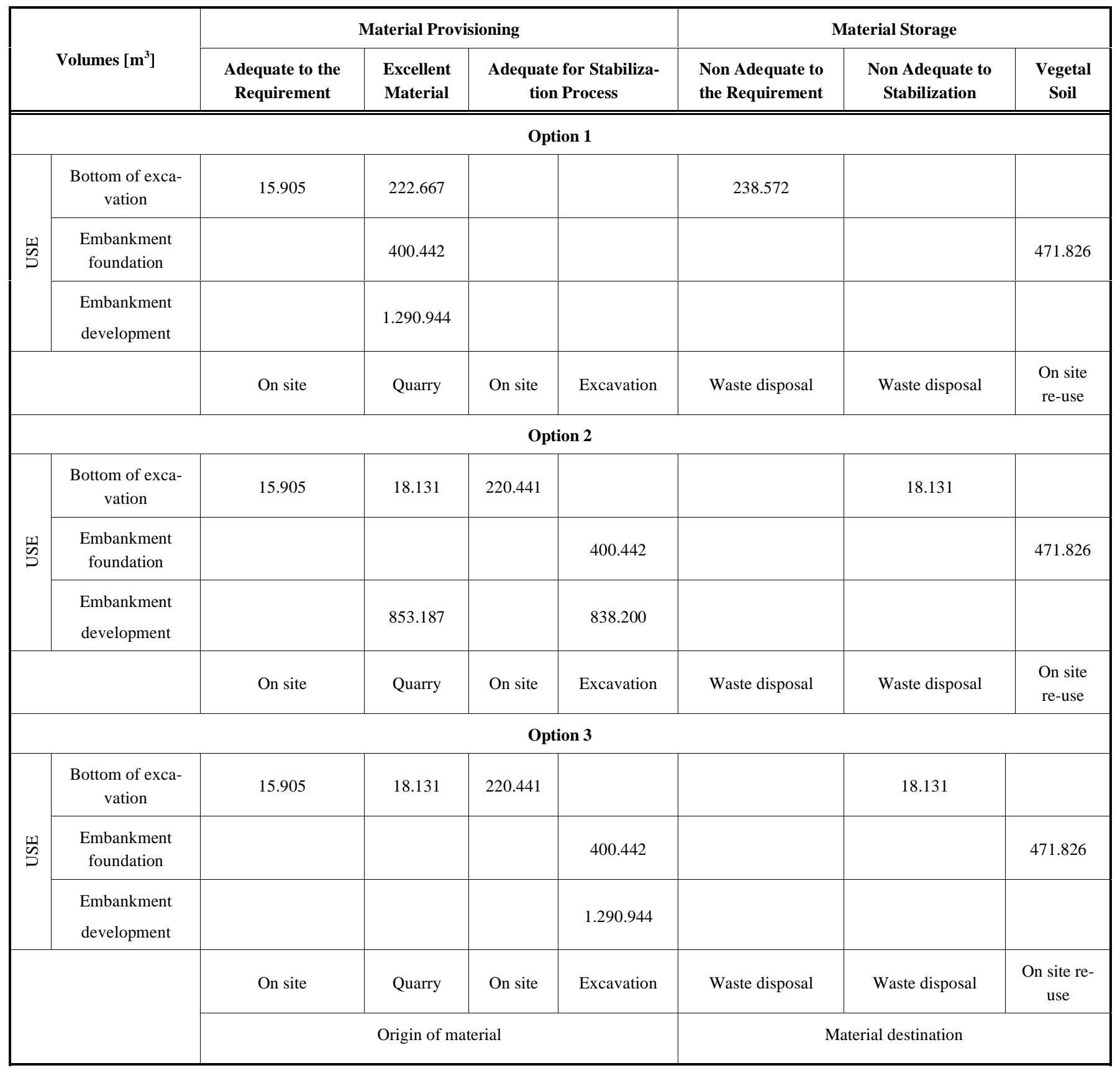

course this evaluation is a first approximation; however it is evidence that recycling after stabilization has a relevant positive impact on financial cost (Fig. 10).

According to the methodology mentioned in section 3 the magnitude of these environmental impacts has been evaluated as the amount of savings from the reduction of waste disposal and recycling of materials.

The Environmental Impact Assessment does not consider soil stabilization as environmental impact mitigation and demonstrates that the most relevant impact is noise pollution, and secondly interferences with surface and ground water. But the costs for noise mitigation are much higher rather than costs for the reduction of all the other environmental impacts (excluding soil disposal and natural material consumption).

Actions and interventions for noise abatement for national regulation standards has been developed, according to the outcomes of simulation software (MITHRA) for noise prediction. The estimated costs for the implementation of such a project are about 500,000€.

Moreover numerous actions have been planned as a result of the Environmental Impact Assessment to mitigate interferences with the natural surface hydraulic network. The following main actions are part of the environmental project: (1) ponds for pollutants entrapment and river protection dur- 
Table 5. Comparison of Construction Costs

\begin{tabular}{|c|c|c|}
\hline & & Costs \\
\hline \multirow{3}{*}{ 苛 } & Excellent material from quarries A & $€ 15.494 .721$ \\
\hline & Excellent material from quarries $\mathrm{C}$ & $€ 3.645 .817$ \\
\hline & Waste disposal & $€ 596.430$ \\
\hline \multirow{5}{*}{ 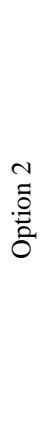 } & Excellent material from quarries $\mathrm{A}$ & $€ 7.053 .528$ \\
\hline & Excellent material from quarries B & $€ 1.244 .740$ \\
\hline & Excellent material from quarries $\mathrm{C}$ & $€ 1.659 .654$ \\
\hline & Waste disposal & $€ 45.329$ \\
\hline & Total & $€ 14.970 .148$ \\
\hline \multirow{5}{*}{ 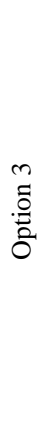 } & Excellent material from quarries A & $€ 146.779$ \\
\hline & Excellent material from quarries B & $€ 25.902$ \\
\hline & Excellent material from quarries $\mathrm{C}$ & $€ 34.536$ \\
\hline & Stabilization of soil (on site) & $€ 859.718$ \\
\hline & Stabilization of soil (from excavation) & $€ 8.287 .794$ \\
\hline
\end{tabular}

ing construction, (2) river banks protection and stabilization through ecological works, (3) avoiding bridge piles into riverbeds, (4) hydraulic isolation of yards and construction sites to avoid any eventual rain or runoff contamination, (5) waste water treatment before discharging. The protection of ground water is an important part of the environmental project considering that the piezometric level is approximately only a few centimetres deep, and no soil buffer or isolation exists. The main actions to mitigate impacts on ground water are (1) the construction of drainage systems to reduce the risk of polluted water infiltration, (2) permanent or temporary paving of work sites and roads where the risk of accidental pollutant discharge is not negligible.

Other minor local actions have been planned to reduce or eliminate environmental impacts to flora and fauna. The total costs for water protection and ecological impacts mitigations are about $200,000 €$.

It means that the total costs of all the actions derived from the Environmental Impact Assessment for environment protection is less than $1,000,000 €$. This is only about $8 \%$ of the savings produced by the stabilization of soil from option 1 to option 3. In fact in the case of option 1 (no stabilization) the construction cost is $22,471,331 €$ and in the case of op- tion 3 (maximum stabilization of soil) it is $9,400,058 €$, which yields and estimated saving of $13,071,273 €$.

\section{CONCLUSION}

The construction of the High Speed Railway and the consequent operations of the HS Train have relevant impacts on the environment. The traditional approach of the Environmental Impact Assessment is effective noise and vibration mitigation, water protection, flora, fauna and ecological systems preservation. However, the question of non-renewable resource management, such as soil, is underestimated. Soil that is used for construction purposes has to have adequate mechanical characteristics. In certain geographical regions the traditional abundance of such resources from quarries and strong lobbies of waste and material natural management discouraged the use of alternative materials or recycling. These are the main reasons why this issue is usually underestimated in the Assessments. The case study of the High Speed Railway in North Italy, one of the most important national projects for transportation infrastructure in the last 20 years, demonstrates that the costs for environmental systems protection are much lower than the saving induced by soil stabilization and recycling. In conclusion it is not ac- 


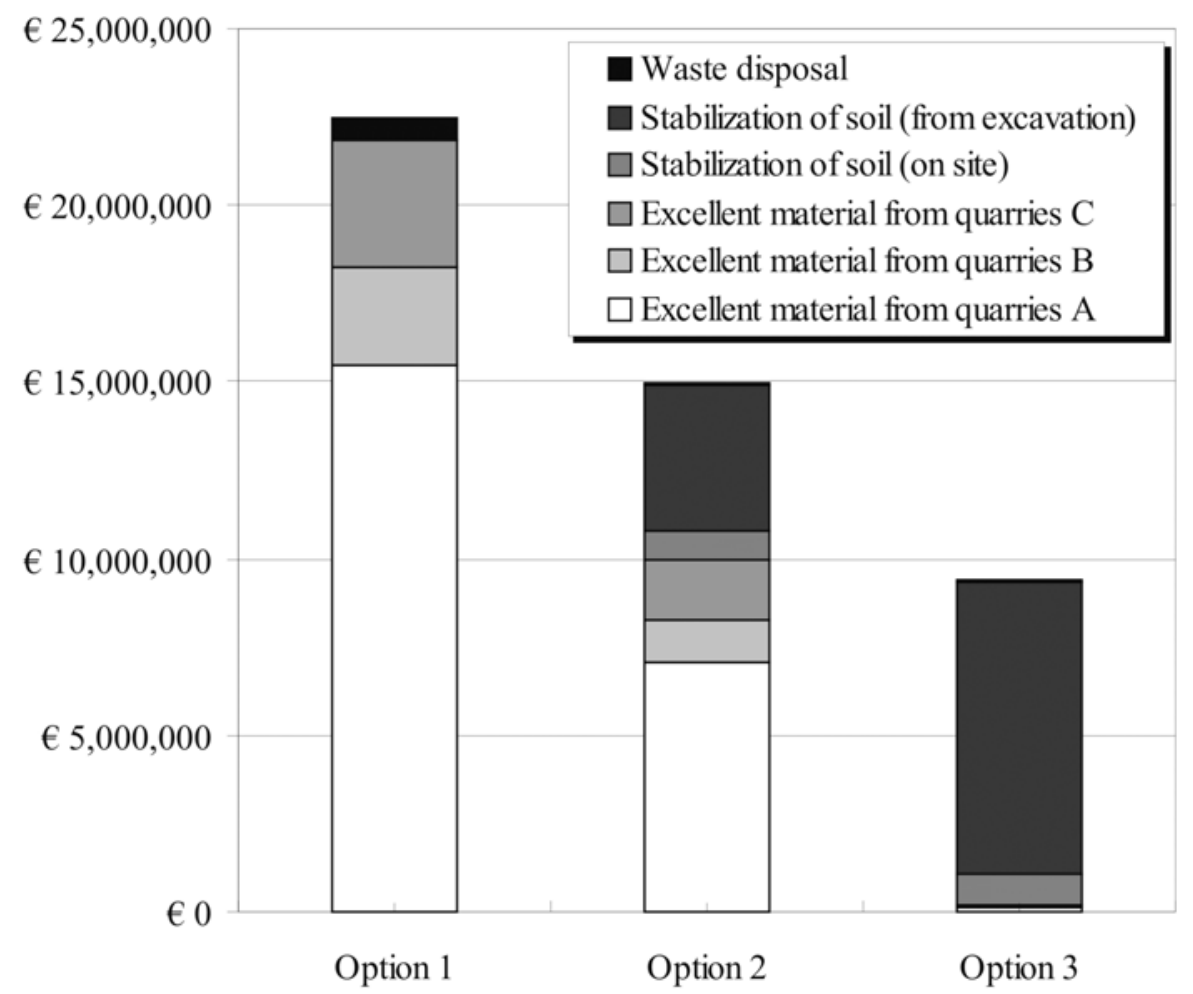

Fig. (10). Construction costs option 1, 2 and 3.

ceptable that such issues are neglected under an environmental assessment and considered only as an eventual strategy for monetary savings.

\section{ACKNOWLEDGMENTS}

The author is grateful to Dr. Sdoga and Dr. Marino and Italferr for assistance and help during this work. Moreover the author is very grateful to Dr. De Stefani for help in data processing.

\section{REFERENCES}

[1] D.A. Hensher, and K.J. Button, Handbook of Transportation and Environment. Oxford: Elsevier Science Ltd.: 2003.

[2] C. McDowell, "Stabilization of soils with lime, lime-flyash and other lime reactive materials", Highway Research Board Bulletin, vol. 231, pp. 60-66, 1959.

[3] D.E.J. McCaustland, Lime dirt in roads, Proceedings of National Lime Association, vol. 7, pp. 12-18, 1925.

[4] K.E. Clare, and A.E. Cruchley, "Laboratory experiments in the stabilization of clays with hydrated lime", Geotechnique, vol. 7, pp. 97-110, 1957.

[5] B.W. Meade, and D.L. Allen, Evaluation of lime stabilized subgrade, Report KTC-93-25, Kentucky Transportation center, Univ. Lexington, 1993.

[6] A.J. Puppala, L.N. Mohammad, and A. Allen, "Engineering behaviour of lime-treated Louisiana subgrade soil", TRR, vol. 1546, pp. 24-31, 1996.

[7] B.S. Qubain, E.J. Seksinsky, and J. Li, "Incorporating subgrade lime stabilization into pavement design", TRR, vol. 1721, pp. 3-8, 2000.

[8] F.A.M. Shafee Yusuf, D.N. Little, and S.L. Sarkar, "Evaluation of structural contribution of lime stabilization of subgrade soils in Mississippi”, TRR, vol. 1757, pp. 22-31, 2001.

[9] G. Vorobieff, and G. Murphy, "A new approach to pavement design using lime stabilized subgrades", In: Proceedings of the $21^{\text {st }}$ $A R R B$ and $11^{\text {th }}$ REAAA Conference. Transport. Our Highway to a Sustainable Future, Vermont South, Australia, 2003.
[10] J.D. Nelson, and D.J. Miller, Expansive Soils: Problems and Practice in Foundation and Pavement Engineering, UK: Wiley Europe, 1997.

[11] A.S. Al-Homoud, T. Khedaywi, and A.M. Al-Ajlouni, "Engineering and environmental aspects of cutback asphalt (MC-70) stabilization of swelling and collapsible soils", Environmental \& Engineering Geoscience, vol. 1(4), pp. 497-506, 1995.

[12] E.M .Frempong, "Field compaction control studies on road bases in a new settlement area in Ghana", Geotechnical \& Geological Engineering, vol. 13(4), pp. 227-241, 1995.

[13] E.M. Frempong, and K.E.N. Tsidzi, "Blending of marginally suitable tropical sub-base materials for use in base course construction”, Construction and Building Materials, vol. 13, pp. 129-141, 1999.

[14] P.V. Sivapullaiah, J.P. Prashanth, A. Sridharan, and B.V. Narayana, "Reactive silica and strength of fly ashes", Geotechnical Geological Engineering, vol. 16, pp. 239-250, 1998.

[15] S.M. Rao, B.V.V. Reddy, and M. Muttharam, "The impact of cyclic wetting and drying on the swelling behaviour of stabilized expansive soils", Engineering Geology, vol. 60, pp. 223-233, 2001.

[16] Z. Nalbantoglu, and E. Gucbilmez, "Improvement of calcareous expansive soils in semi-arid environments", Journal of Arid Environments, vol. 47, pp. 453-463, 2001.

[17] D.I. Boardman, S. Glendinning, C.D.F. Rogers, and C.C. Holt, "In situ monitoring of lime stabilized road subgrade", TRR, vol. 1757, pp. 3-13, 2001.

[18] D.N. Little, Evaluation of structural properties of lime stabilized soils and aggregates, National Lime Association, Vol. 1 Summary and findings, 1999.

[19] Anon, Lime stabilization construction manual, $8^{\text {th }}$ ed, Arlington VA, USA: National lime Association, 1985.

[20] Anon, Lime Stabilization Manual, British Aggregate Construction Materials Industry, London, UK, 1990.

[21] FHWA, "Lime in soil stabilization", Report No: FHWA-HI-93031, Washington DC, USA, 1993.

[22] D.N. Little, Stabilization of Pavement Subgrades and Base Courses with Lime, USA: Kendal/Hunt Publishing Company 1995.

[23] D.N. Little, "Mixture Design and Testing Protocol for Lime Stabilized Soils", Evaluation of Structural Properties of Lime Stabilized Soils and Aggregates, US: National Lime Association, 2000, Vol. 3. 
[24] C.D.F. Rogers, and S. Glendinning, "Lime requirement for stabilization", TRR, vol. 1721, pp. 9-18, 2000.

[25] P.T. Sherwood, Soil Stabilization with Cement and Lime: State of the Art Review, Transportation research laboratory, Her Majesty's stationery office, London, UK, 1993.

[26] LIME National Lime Association, "Lime-treated soil construction manual - lime stabilization \& lime modification", Bulletin 326, 2004.

[27] F.G., Bell, "Lime stabilization of clay minerals soils", Engineering Geology, vol. 42, pp. 223-237, 1996.

[28] M.R. De Blasiis, and M.V. Mieli, "La stabilizzazione a calce delle terre a matrice argillosa. Analisi delle criticità delle variabili", Quarry and Construction, vol. 3. pp. 95-112, 2001.
[29] D.N. Little, T. Scullion, P.B.V.S. Kota, and J. Bhuiyan, "Identification of the structural benefits of base and subgrade stabilization", Report No: FHWA/TX-94/1287-2, Austin, USA, 1995.

[30] D.N. Little, and F.A.M. Shafee Yusuf, Example problem illustrating the application of the national lime association MDTP to ascertain engineering properties of lime-treated subgrades for mechanistic pavement design/analysis, Evaluation of Structural Properties of Lime Stabilized Soils and Aggregates, National Lime Association, 2001, Vol. 4.

[31] D.N. Little, and J.A. Epps, The Benefits of Hydrated Lime in Hot Mix Asphalt, US: National Lime Association, 2001.

(c) Andrea Benedetto; Licensee Bentham Open.

This is an open access article licensed under the terms of the Creative Commons Attribution Non-Commercial License (http://creativecommons.org/licenses/by-nc/3.0/g) which permits unrestricted, non-commercial use, distribution and reproduction in any medium, provided the work is properly cited. 